\title{
Stimulasi Magnetik Lebih Meningkatkan Kemampuan Fungsional pada Pasien Nyeri Punggung Bawah Dibanding Stimulasi Elektris
}

\author{
Heru Purbo Kuntono', M. Mudatsir Syatibi ${ }^{2}$, Aditya Johan Romadhon ${ }^{3 *}$ \\ ${ }^{1,2,3}$ Poltekkes Kemenkes Surakarta Jurusan Fisioterapi \\ E-mail: adityajohan.rom@gmail.com
}

\begin{abstract}
Background: A long with the development of physical agents modalities, there are many recent modalities that has many beneficial for physical therapy practice, generally physical agents modalities are suit for musculoskeletal cases, one of beneficial effect for musculoskeletal case is maintaining of muscle's physiology, electrical stimulations are familiar modalities that usually find in physiotherapy practice, these modalities are use to inhibit pain signal and produce muscle contraction. Recently a new physical agent modality such as magnetic stimulation also has smiliar effect such as electrical stimulations, however there are less evidence to compare magnetic and electrical stimulation for musculoskeletal problems. Objective: Purpose of this study is to compare magnetic and electrical stimulation effect to reduce pain and improve functional activity in low back pain patients. Methods: Random of 60 low back pain patients were recruited, devided into two groups, Group 1 given magnetic stimulation and Group 2 given electrical stimulation, after four mounth intervention two days in every weeks, pain index and functional activity measured with Oswestry instrument, inclusion criteria for subjects was pain symptom less than 1 year, 25-65 years old, there's no neurologic deficit, married and cooperative to be subject. Exclusion criteria of subject was lumbo-sacral fracture condition, pregnancy, subject with heart disease, osteophorosis, or systemic disease. Data analyzed by dependent and independent $t$ test. Results: based on the result by using independent $t$ test, we have $p$ value 0.001 , it means there's significant different between two groups. After 4 mounth intervention we find reducing pain index and improvement of functional activity in two groups, Group 1 the Oswestry score is $0.2 \pm 0.08$, while Group 2 the Oswestry score is $0.3 \pm 0.05$. Conclussion: magnetic stimulation is more effective to reduce pain index and improve functional activity by using Oswestry instrument than electrical stimulation.
\end{abstract}

Keywords: a delta fiber, c fiber, electrical, magnetic, stimulation

\section{PENDAHULUAN}

Nyeri Punggang Bawah (NPB) merupakan sebuah gejala nyeri yang dikeluhkan pada punggung bagian bawah, berbagai macam struktur spinal seperti ligamen, facet sendi, otot par vertebral, diskus, akar saraf merupakan pencetus nyeri, meskipun demikian $85 \%$ pasien yang menderita NPB tidak ditemukan penyebab yang jelas. Terjadinya NPB dapat ditimbulkan oleh penyebab mekanik, sistemik dan penjalaran, namun sebagian besar NPB disebabkan oleh mekanik (Gianola et al, 2019).

Nyeri punggung bawah terjadi pada semua kultur dengan proporsi yang sama, di negara berkembang seperti Indonesia secara umum nyeri punggung bawah mengenai sekitar $70 \%$ penduduk dewasa. Dilaporkan $80 \%$ - $90 \%$ penduduk Amerika pernah mengalami keluhan ini sepanjang hidupnya dan $30 \%$ menjadi kronis jika berlangsung lebih dari tiga bulan (Ariotejo, 2009).

Nyeri punggung bawah adalah nyeri yang dirasakan didaerah punggung bawah, ditandai dengan rasa pegal saat otot berkontraksi statis dalam waktu lama, nyeri dapat bersifat lokal maupun menjalar atau kedunya. NPB dikeluhkan dapat berupa rasa berat, pegal, rasa seperti diikat, otot terasa kaku dan nyeri, dapat 
disertai dengan gangguan otonom dan psikis yang menghambat aktivasi seharihari penderita (Albar, 2000).

Nyeri punggung bawah bukan penyakit spesifik, lebih merupakan gejala yang terjadi dari berbagai proses yang berbeda - beda. Lebih dari $85 \%$ pasien dengan nyeri punggung bawah meskipun telah dilakukan pemeriksaan medis, penyebab nyeri tidak dapat dikenali secara spesifik. Penyebab Nyeri Punggung Bawah (NPB) dibedakan menjadi empat pola klinis antara lain NPB mekanik simpel, NPB dengan radiculopathy, NPB patologis yang serius dan NPB dengan beban psikologis (Ariotejo, 2009).

Nyeri yang dirasakan pada daerah punggung bawah, dapat merupakan nyeri lokal (inflamasi), nyeri radikuler, ataupun keduanya, yang dapat merujuk ke daerah lain atau sebaliknya yang berasal dari daerah lain yang dirasakan pada daerah punggung bawah (reffered pain). Nyeri punggung bawah kronis dapat menyebabkan penurunan mobilitas, disabilitas jangka panjang dan penurunan kualitas hidup dan hal ini merupakan penyebab utama ketidakhadiran dalam bekerja.

Menurunkan kualitas nyeri, meningkatkan kemampuan fungsional merupakan tujuan utama dalam melakukan bentuk pendekatan pada penderita nyeri punggung bawah(Bull \& Archard, 2007). Dengan demikian fisioterapi mempunyai peranan yang besar dalam penanganan pasien dengan nyeri punggung bawah dengan modalitas yang ada. Modalitas yang dipakai antara lain: massage, terapi panas / dingin, stimulasi listrik, EMG biofeedback, terapi UltraSound, terapi latihan, stimulasi magnetic serta kombinasi beberapa intervensi (Bogduk, 2005).
Stimulasi magnetik semakin diterapkan dalam konteks konservatif dari penyakit sistem alat gerak. Karena perubahan waktu yang cepat dan akurat dari medan magnet intensitas tinggi, bouncing dari tegangan listrik yang diinduksi dan akibatnya arus listrik yang diinduksi terbentuk pada jaringan. Gradien dari tegangan listrik yang diinduksi dalam akson saraf sudah cukup tinggi untuk penciptaan dan penyebaran stimulus yang diinduksi, stimulasi terjadi pada saraf afferent berpenampang tebal ABeta, sehingga stimulus nyeri pada otot punggung bawah terinhibisi (Bahrens \& Bainert, 2014). Penelitian yang menyelidiki efek dari pengobatan stimulasi magnetik untuk pengurangan nyeri dan pemulihan fungsional pasien dengan nyeri punggung bawah akut pada 26 pasien yang dilakukan $10 \mathrm{X}$ tindakan terapi menunjukkan pengurangan nyeri yang signifikan setelah setiap sesi dan terjadi perbaikan fungsional (Hills, 2001).

Untuk mengetahui hasil yang lebih baik antara pemberian stimulasi magnetik dan stimulasi listrik dalam peningkatan fungsional pada pasien nyeri punggung bawah menggunakan oswestry disability index.

\section{METODE PENELITIAN}

Jenis penelitian adalah true experimental dengan pre and post test design, dengan menggunakan uji analisis dependent $t$ test dan independent $t$ test. Penelitian ini penulis mempergunakan data primer yaitu dengan melakukan pencatatan data sebelum dan sesudah terapi pada masing-masing kelompok. Penelitian ini di laksanakan di Praktek Mandiri Fitasoma, dipilih tempat tersebut karena banyaknya pasien dengan kondisi NPB dan di laksanakan pada bulan maret 
sampai Juli 2019. Subjek penelitian sebanyak 60 subjek yang merupakan pasien yang didiagnosis dokter dan fisioterapis menderita NPB yang datang ke Praktek Mandiri Fitasoma pada bulan maret sampai juli 2019, total subjek dibagi menjadi 2, Kelompok $1 \quad(n=30)$ diberikan perlakuan stimulasi magnetic dan Kelompok 2 diberikan perlakuan stimulasi elektris. Frekuensi pemberian 3 kali dalam seminggu pada kelompok 1 dan 2 dan alat ukur yang digunakan oswestry disability index adalah kuesioner disabilitas nyeri punggung bawah oswestri, berupa kuesioner berisi 10 macam pertanyaan dan peneliti meminta subjek untuk memilih salah satu jawaban dari 6 pilihan yang disediakan dengan nilai 0-5 (0 tanpa cacat dan 5 kecacatan paling parah) dengan memberikan tanda cek $(\sqrt{ })$ pada kotak yang disediakan.

\section{HASIL PENELITIAN}

Rerata usia pada kelompok 1 adalah $54 \pm 10.54$ dan rerata usia pada kelompok 2 adalah $52.1 \pm 12.38$, dimana pada kedua kelompok tidak memiliki perbedaan usia yang bermakna dengan ditunjukkan nilai signifikasi $\mathrm{p}>0.05$. Rerata tinggi badan pada kelompok 1 adalah $164 \pm 9.5 \mathrm{~cm}$ dan rerata tinggi badan pada kelompok 2 adalah $163 \pm 7.12 \mathrm{~cm}$, pada kedua kelompok tidak ditemukan perbedaan tinggi badan yang bermakna dengan ditunjukkan signifikasi $\mathrm{p}>0.05$, rerata berat badan pada kelompok 1 adalah $79.83 \pm 11.68 \mathrm{Kg}$ dan rerata berat badan kelompok 2 adalah $73.26 \pm 11.33 \mathrm{Kg}$, rerata berat badan pada kedua kelompok tidak ditemukan perbedaan yang bermakna, rerata lama menderita nyeri pada kelompok 1 adalah $4.68 \pm 2.67$ bulan dan rerata pada kelompok 2 adalah $4 \pm$ 2.47, kedua kelompok tidak memiliki perbedaan lama menderita nyeri yang bermakna dengan nilai signifikasi $\mathrm{p}>0.05$.

Berdasar Tabel 1 rerata skor Oswestry Disability Index sebelum dan sesudah perlakuan pada masing-masing kelompok dilakukan uji normalitas data dan didapatkan distribusi data pada kelompok 1 dan kelompok 2 adalah normal, dengan ditunjukkan nilai $\mathrm{p}>0.05$.

Tabel 1. Uji Normalitas dan Homogenitas Data Skor Oswestry Disability Index pada Kelompok 1 dan Kelompok 2

\begin{tabular}{cccc}
\hline & \multicolumn{3}{c}{ Normalitas } \\
Oswestry Scores & \multicolumn{2}{c}{ Sebelum } & Sesudah \\
\cline { 2 - 4 } & \multicolumn{2}{c}{$\mathbf{p}$} & 0.232 \\
\hline Kelompok 1 & 0.207 & 0.065 \\
Kelompok 2 & 0.085 & 0.98 \\
\hline Homogenitas & \multicolumn{2}{c}{0.54} & dan uji \\
\hline Dengan demikian data & rerata skor & masing-masing & kelompok \\
Oswestry Disability & Index tersebut & independent t test untuk mengetahui \\
selanjutnya dilakukan uji parametrik, & perbedaan rerata skor Oswestry Disability \\
yakni dependent t test untuk mengetahui & Index sesudah perlakuan antara kelompok \\
pengaruh perlakuan terhadap penurunan & 1 dan kelompok 2.
\end{tabular}

rerata skor Oswestry Disability Index pada 
Tabel 2. Analisis Skor Oswestry Disability Index Sebelum Dan Sesudah Perlakuan Pada Kedua Kelompok

\begin{tabular}{cccc}
\hline & Kelompok 1 & Kelompok 2 & \\
& & & $\mathbf{p}$ \\
Oswestry Score & $\overline{\boldsymbol{x}}$, Std & $\overline{\boldsymbol{x}}$, Std & \\
\hline Pre & $0.58 \pm 0.08$ & $0.58 \pm 0.06$ & 0.895 \\
Post & $0.23 \pm 0.08$ & $0.3 \pm 0.05$ & $<0.001$ \\
p & $<0.001$ & $<0.001$ & \\
\hline
\end{tabular}

Berdasarkan tabel 2, rerata skor Oswestry sebelum perlakuan pada kelompok 1 adalah $0.58 \pm 0.08$ dan pada kelompok 2 adalah $0.58 \pm 0.06$, pada kedua kelompok tidak ditemukan perbedaan skor Oswestry sebelum perlakuan yang bermakna dengan ditunjukkan nilai signifikasi $\mathrm{p}>0.05$, rerata skor Oswestry setelah perlakuan pada kelompok 1 didapatkan $0.23 \pm 0.08$ dan pada kelompok 2 didapatkan $0.3 \pm 0.05$, rerata skor Oswestry sesudah perlakuan pada kedua kelompok didapatkan perbedaan yang bermakna, dengan nilai signifikasi $\mathrm{p}<0.05$.

Perlakuan pada masing-masing kelompok mampu menurunkan nyeri dan mampu memberikan perbaikan fungsional pada pasien nyeri punggung bawah, dengan ditunjukkan penurunan rerata skor Oswestry, pada kelompok 1 rerata skor Oswestry sebelum perlakuan adalah 0.58 \pm 0.08 dan sesudah perlakuan rerata skor Oswestry adalah $0.23 \pm 0.08$, signifikasi penurunan rerata skor Oswestry pada kelompok 1 ditunjukkan dengan perbedaan yang bermakna antara rerata skor Oswestry sebelum dan sesudah perlakuan, dengan nilai signifikasi $\mathrm{p}<0.001$, begitu juga pada kelompok 2, rerata skor Oswestry sebelum perlakuan adalah $0.58 \pm 0.06$ dan sesudah perlakuan $0.3 \pm 0.05$, signifikasi penurunan rerata skor Oswestry pada kelompok 2 ditunjukkan dengan perbedaan yang bermakna antara rerata skor Oswestry sebelum dan sesudah perlakuan, dengan nilai signifikasi $\mathrm{p}<0.001$.

Perbandingan rerata skor Oswestry sebelum perlakuan antara kelompok 1 dan kelompok 2 tidak didapatkan perbedaan yang bermakna dengan nilai signifikasi p $>0.05$, hal ini menunjukkan bahwa pada awal sebelum perlakuan kedua kelompok memiliki rerata skor Oswestry yang identik, dimana rerata skor Oswestry kelompok 1 adalah $0.58 \pm 0.08$ dan rerata skor Oswestry kelompok 2 adalah $0.58 \pm$ 0.06 .

Perbandingan rerata skor Oswestry sesudah perlakuan antara kelompok 1 dan kelompok 2 didapatkan perbedaan yang bermakna dengan nilai signifikasi $\mathrm{p}<0.001$, dimana rerata skor Oswestry pada kelompok 1 adalah $0.23 \pm 0.08$ dan rerata skor Oswestry pada kelompok 2 adalah $0.3 \pm 0.05$.

Berdasarkan analisis tersebut maka perlakuan pada kelompok 1 lebih mampu dalam mengurangi nyeri pada pasien nyeri punggung bawah dibanding perlakuan pada kelompok 2, hal ini ditunjukkan dengan hasil rerata skor Oswestry sesudah perlakuan pada kelompok 1 lebih rendah dibanding hasil rerata skor Oswestry sesudah perlakuan pada kelompok 2 .

\section{PEMBAHASAN}


Reseptor nyeri dapat distimulasi melalui stimulus mekanis, thermal, kimia. Stimulus ini akan di respon dengan timbulnya inflamasi yang akan menimbulkan presepsi nyeri. Mekanisme nyeri merupakan proteksi yang bertujuan untuk mencegah pergerakan sehingga proses penyembuhan dimungkinkan terjadi. Spasme otot merupakan salah satu proteksi nyeri yang akan menimbulkan vasokontriksi pembuluh darah yang menyebabkan ischemia yang sekaligus menjadi titik nyeri (trigger point) (Chameron, 2013).

Cedera punggung bawah akan menstimulus reseptor nyeri (nosisseptor) yang menyebabkan rusaknya membran sel, menghasilkan sintesa enzim saat terjadi ekstravasasi. Salah satunya yaitu substansi "P" yang akan meningkatkan mikrosirkulasi lokal dan ekstravasai plasma yang menyebabkan chemical sehingga stimulus nyeri terjadi. Nyeri yang terjadi menyebabkan penderita takut bergerak sehingga terjadi penurunan mobilitas sendi tulang belakang dan terjadi keterbatasan fungsional punggung bawah. Karena hal tersebut penderita mengambil posisi yang paling nyaman tanpa memperhatikan posisi yang benar, bila dibiarkan terus akan menghambat kesembuhan bahkan dapat memburuk keadaan ( Bogduk, 2005).

Berdasarkan mekanismenya maka nyeri yang terjadi pada nyeri punggung bawah adalah nyeri nosiseptif, nyeri nosiseptif terjadi jika ujung-ujung saraf perifer utuh (nosiseptor) distimulasi oleh stimulus berbahaya seperti luka (akibat panas, mekanik atau kimia), penyakit dan peradangan. Nyeri ini terjadi karena aktifitas terus-menerus dari nosiceptor A$\delta$ dan $\mathrm{C}$ dalam merespon stimulus yang berbahaya (Bahrens \& Bainert, 2014).
Respon bisa berupa menginhibisi nyeri dengan pengeluaran endorphin, maupun melalui mekanisme proteksi area nyeri dengan mekanisme respon reflek spinal segmental yang menyebabkan spasme otot dan vasokontriksi.

Adanya spasme otot dan vasokontriksi pembuluh darah disekitar nyeri maka akan terjadi iskemia jaringan dan sekaligus menjadi titik picu atau triger point terjadinya nyeri punggung bawah (Chameron, 2013).

Stimulasi magnetik super inductive system, memberikan efek perbaikan jaringan menggunakan medan magnetik berfrekuensi tinggi, merupakan terapi yang sesuai dalam menurunkan nyeri pada kondisi muskuloskeletal. Prinsip dasar modalitas terapi ini adalah interaksi antara frekuensi tinggi medan magnetik dan tubuh pasien.

Ketika modalitas ini di aplikasikan pada jaringan neuromuskuler, maka akan terjadi depolarisasi dan kontraksi otot, kontrol penurunan nyeri yang disebabkan oleh depolarisasi jaringan neuromuskuler didapat melewati 3 mekanisme neurofisiologis, sebagai contoh endogenous opoid, gate control dan inhibisi tingkat perifer (Firmino, 2017).

Kekuatan bidang magnet $(\mathrm{H})$, diukur dengan ampere per meter $(\mathrm{A} / \mathrm{m})$. Magnetic flux density $B$, diukur dengan $(\mathrm{Nm} / \mathrm{A})$, disebut juga dengan istilah Tesla (T). Bidang magnet dapat divisualisasikan sebagai garis-garis bidang magnet. Kekuatan bidang berhubungan dengan kepadatan garis bidang. Jumlah total garis bidang magnet yang masuk ke area ini disebut magnetic flux yang diukur dengan Tesla dikalikan dengan meter persegi ( $\mathrm{T} \mathrm{x}$ $\mathrm{m} 2$ ), disebut juga dengan istilah Weber $(\mathrm{Wb})$. Efek terapeutik penggunaan stimulasi magnetik adalah modulasi nyeri, 
myostimulation, peningkatan Lingkup Gerak Sendi (LGS), kontrol spastisitas, mengaktivasi penyembuhkan fraktur (American Physical Therapy Association, 2001).

Inductive coil menghasilkan bidang magnet yang berbentuk sinus dan berdenyut (pulsed). Bidang magnetic menginduksi bidang elektris yang cukup kuat untuk depolarisasi jaringan neuromuscular. Parameter efek terapi adalah frekuensi dan kekuatan bidang induksi (inductive field). Penggunaan stimulasi magnetik ditujukan pada stimulus saraf, akar saraf, saraf tepi terutama serabut saraf aferent berpenampang tebal (a-beta), mobilisasi sendi akibat kontraksi otot skeletal (Bahrens \& Bainert, 2014).

Aplikasi stimulasi magnetik pada penelitian ini yaitu dengan nyeri akut dengan frequency $10-15 \mathrm{~Hz}$, mengaktivasi a beta, intensitas normalis, nyeri kronis dengan frequency $10-25 \mathrm{~Hz}$, intensitas fortis sampai timbul kontraksi jelas dan nyeri neuropatik frequency $2-10 \mathrm{~Hz}$, ditujukan untuk merelease endorphins (Chameron, 2013)

Stimulasi Listrik merupakan suatu cara penggunaan energi listrik yang berguna untuk merangsang sistem saraf melalui permukaan kulit dan terbukti efektif untuk mengurangi berbagai tipe nyeri. Penerapan energi listrik dalam berbagai bentuk gelombang, amplitudo, dan frekuensi untuk saraf perifer melalui elektroda (Parjoto dkk, 2004).

Stimulasi listrik memiliki beberapa spesifikasi yaitu: (1) target arus untuk mengaktivasi saraf berdiameter besar, (2) serabut yang teraktivasi A- $\beta$, mekanoreseptor, (3) sensasi yang timbul adalah parestesia yang kuat sedikit kontraksi, (4) karakteristik fisikanya frekuensi tinggi, intensitas rendah, pola kontinyu dengan durasi yaitu 100-200 $\mu \mathrm{s}$, dan frekuensinya $10-200 \mathrm{~Hz}$, (5) posisi elektrode pada titik nyeri dermatom, (6) profil analgetiknya yaitu akan terasa kurang dari 30 menit setelah dinyalakan dan menghilang kurang dari 30 menit setelah alat dipadamkan, (7) durasi terapi secara terus menerus saat nyeri terjadi, (8) mekanisme analgetik yaitu pada tingkat segmental (Parjoto dkk, 2004).

Stimulasi listrik menghasilkan efek analgesik terutama melalui mekanisme segmental yaitu dengan mengaktivasi serabut $A \beta$ yang selanjutnya akan menginhibisi neuron nosiseptif di kornu dorsalis medula spinalis, ini mengacu pada teori gerbang kontrol (gate control theory) (Bahrens \& Bainert, 2014) yang menyatakan bahwa gerbang terdiri dari sel internunsial yang bersifat inhibisi yang dikenal sebagai substansia gelatinosa (SG) dan yang terletak dikornu posterior dan sel $\mathrm{T}$ yang mendapat informasi dari pusat yang lebih tinggi. Tingkat aktivitas sel $\mathrm{T}$ ditentukan oleh keseimbangan asupan dari serabut berdiameter besar A- $\beta$ dan A- $\alpha$ serta serabut berdiameter kecil $A-\delta$ dan serabut C.

Asupan dari serabut saraf berdiameter kecil akan mengaktivasi sel $\mathrm{T}$ yang kemudian dirasakan sebagai keluhan nyeri. Jika serabut berdiameter teraktivasi maka akan mengaktifkan sel $\mathrm{T}$, tetapi pada saat yang bersamaan impuls juga memicu sel SG dan berdampak pada penurunan asupan terhadap sel $\mathrm{T}$ baik yang berasal dari serabut yang berdiameter besar maupun kecil. Impuls dari serabut berdiameter besar akan menutup gerbang dan akan membloking transmisi impuls dari serabut aferen nosiseptor sehingga nyeri berkurang atau menghilang (Parjoto dkk, 2004). 


\section{KESIMPULAN}

Hasil yang didapat dari penelitian, pemberian stimulasi magnetik dapat menurunkan nyeri dan meningkatkan kemampuan fungsional pasien lebih baik daripada pemberian stimulasi listrik. Penggunaan stimulasi magnetik mampu sekaligus menghambat atau inhibisi nyeri melewati 3 mekanisme, baik inhibisi pada tingkat spinal maupun tingkat supraspinal, selain itu penggunaan medan magnetik frekuensi tinggi mampu mempercepat penyembuhan melewati perbaikan vaskuler, sehingga bentuk nyeri yang didapat dari gangguan otot, tulang dan jaringan lunak lainnya dapat dikurangi dengan perbaikan struktur jaringan tersebut.

\section{DAFTAR RUJUKAN}

Albar, Z. (2000). Sistematika Pendekatan pada Nyeri Pinggang. Cermin Dunia Kedokteran, hal. 14-19.

Alexandria. (2001). American Physical Therapy Association: Electrotherapeutic Terminology, Physical Therapy. Section on Clinical Electrophysiology

Ariotejo, B. (2009). Nyeri Punggung Bawah; Diakses tanggal 10/9/2013.http://bimoariotej0.files.w ordpress.com/2009/09/31.jpg.

Bahrens \& Bainert. (2014). Physical Agents: Theory and Practice. FA Davis Company. Phladelphia

Bogduk, N. (2005). Clinical Anatomy of The Lumbar Spine and Sacrum 4th
Edition; Churchil Livingstone, Toronto, hal 34-39.

Chameron, M.H. (2013). Physical Agents in Rehabilitation From Research to Practice. Portland

Firmino Telmo. (2017). Super Inductive System The Ultimate Rehabilitation Modality in Football Sports Medicine. Barcelona Spain.

Gianola Silvia, Castellini Greta, Andreano Anita, Corbetta Davide, Frigerio Pamela, Pecoraro Valentina, Redaelli Valentina, Tettamanti Andrea, Turolla Andrea, Lorenzo Moja, Valsecchi Maria G. (2019). Effectiveness of treatments for acute and sub-acute mechanical nonspecific low back pain: protocol for a systematic review and network meta-analysis.

Hills E.C. (2001). Mechanical Low Back Pain; eMedicine; Diakses tanggal 10/9/2013.http://www.emedicine.co $\mathrm{m} / \mathrm{pmr} /$ topic73.htm.

Parjoto, S dkk. (2004). Perbandingan Efek Terapi Arus Interferensi dengan Tens dalam Pengurangan Nyeri pada Penderita Nyeri Punggung Bawah Muskuloskeletal; TITAFI XIX, Jogjakarta

K. H. Polasek, H. A. Hoyen, M. W. Keith, R. F. Kirsch and D. J. Tyler. (2009). "Stimulation Stability and Selectivity of Chronically Implanted Multicontact Nerve Cuff Electrodes in the Human Upper Extremity," in IEEE Transactions on Neural Systems and Rehabilitation 
Engineering, vol. 17, no. 5, pp. 428437. 